Original Research Article

\title{
Comparative study of knowledge, attitude and practice of self- medication among undergraduate students of MBBS and BDS
}

\author{
Neelam Rani, Shamiya Sadiq*, Kanika Khajuria
}

Department of Pharmacology and Therapeutics, GMC-Jammu Government Medical College, Jammu, J\&K, India

Received: 27 October 2018 Accepted: 04 November 2018

*Correspondence to:

Dr. Shamiya Sadiq, Email: drshamiya31621@ Gmail.com

Copyright: (C) the author(s), publisher and licensee Medip Academy. This is an openaccess article distributed under the terms of the Creative Commons Attribution NonCommercial License, which permits unrestricted noncommercial use, distribution, and reproduction in any medium, provided the original work is properly cited.

\begin{abstract}
Background: Comparative studies are quite useful in evaluating the current practices in self medication among a similar subset of population. Since, self medication is one of the major causes of promoting irrational use of drugs its burden needs to be estimated more so in students with medical background.

Methods: The study was conducted in a tertiary care teaching medical college among MBBS and BDS students. A questionnaire was selected based on outcome of small surveys done prior to this current study was among the MBBS and BDS students to assess their Knowledge, attitude and practice (KAP) towards self medication. Data was analyzed and expressed as numbers and percentage.

Results: Total 180 students participated in the study voluntarily (100 MBBS and 80 BDS). Knowledge regarding self medication was more seen in MBBS students as compared to dental students. Only five of MBBS students encountered ADR's(Adverse drug reactions) due to self medication. Analgesic group of drugs was the most common medication used by both the groups and pain was the chief component for which drug therapy was used.

Conclusions: This study showed that students had fair knowledge about self medication but it appeared to be more among MBBS students as compared to BDS, although knowledge about ADR's was not up to the mark. The attitude and practice of self medication was similar in both the groups. Thus, it is important to impart proper knowledge about self medication among medical students and encouragement regarding ADR teaching should be promoted.
\end{abstract}

Keywords: ADRs, Dental, KAP, Self-medication, Questionnaire, Undergraduate

\section{INTRODUCTION}

Self medication is defined as obtaining and consuming the medicine without advice of physician. It has both positive and negative aspects. On one hand it saves time to consult physician and on the other hand it lessens the burden on healthcare infrastructure which is very important especially in the developing countries where resources are less. ${ }^{1}$ However, the irrational medication can have a negative outcome in some and may have an epidemiological impact on society as it can lead to resistance, adverse reactions, interactions, drug dependence beside wasting financial resources. ${ }^{2,3}$ Easy availability and lesser stringent application of drug controlling rules in India, further can also be a deciding factor in promotion of self medication. ${ }^{4}$

India ranks $3^{\text {rd }}$ in the world as per the volume of production of medicines is concerned and the Indian Pharmaceutical industry had more than turnover of 36.7 billion US Dollar in year 2017 and projected to grow to USD 55 billion by $2020 .^{5}$

Medical students form a unique population as they have access to the medicines and are also equipped with basic knowledge of uses of these drugs. Thus, they are more 
prone to indulge in self medication compared to the general population.

There are number of studies evaluating the knowledge, Attitude and Practice among medical students. But there are a few studies regarding comparison of KAP among medical and dental students. Dental students like medical students are imparted knowledge about medicines during their second professional study course in subjects of pharmacology and microbiology. The pharmacology curriculum as well as microbiology both deal with study of these drugs, their application, dosage, adverse drug reactions, uses, sensitivity of organisms which can be a yardstick to evaluate the resistance.

However, during review of literature, authors came across very limited studies regarding comparative evaluation among MBBS and Dental students. Therefore, the present study was conceived to evaluate knowledge, Attitude and Practice among medical and dental students and compare them during their $2^{\text {nd }}$ professional course.

\section{METHODS}

This cross-sectional, observational, questionnaire based study was done among $2^{\text {nd }}$ professional students of MBBS and BDS attending theory classes in the Department of Pharmacology, GMC Jammu after getting approved by IEC vide order no IEC/2018/583.The questionnaire was divided into two parts. The first part comprised a set of questions based on the demographic profile of the students and the second part contained questions based on knowledge (6each), attitude (6each) and practice (5each) towards self-medication. Questionnaire elucidating details about the various indications for the use of selfmedication, nature of drugs used and sources of information regarding self-medication were also included.

The questions were selected based on outcome of small survey done among small group of medical and dental students prior to the current trial and the answers were taken in Yes and No. A brief description about the objectives of the study were explained to the students before filling up the questionnaire and the time allotted to fill it up was 20 to 30 minutes. All $2^{\text {nd }}$ prof students who voluntarily accepted to participate in the study were included and only completely filled forms were assessed for final analysis. The identity of the students was kept confidential. The data was calculated, and the results were presented in number and percentage.

\section{RESULTS}

A total of 180 subjects, 100 MBBS and 80 BDS second professional participated in the study. Out of 180, 80 were Males and 98 were females. Average age of the volunteers was 20-23 of age (Table 1).

Table 1: Demographic profile of study population.

\begin{tabular}{|ll|l|}
\hline Parameters & MBBS & BDS \\
\hline Total number of subjects & 100 & 80 \\
\hline \multirow{2}{*}{ Sex } & Male-52 & Male-30 \\
\cline { 2 - 3 } & Female-48 & Female-50 \\
\hline Age & $20-23$ & $20-23$ \\
\hline
\end{tabular}

Table 2: Questions pertaining to the knowledge of self medication.

\begin{tabular}{|lllll|}
\hline \multirow{2}{*}{ Questions of knowledge } & \multicolumn{2}{l|}{ MBBS $(\mathbf{n} \%)$} & \multicolumn{2}{l|}{ BDS (n\%) } \\
\hline Are you aware of self medication & Yes & No & Yes & No \\
\hline Do you know about over the counter drugs & $99(99)$ & $1(1)$ & $70(87.5)$ & $10(12.5)$ \\
\hline Do you think that ADRs can be due to Self medication & $89(89.89)$ & $10(10.10)$ & $55(78.57)$ & $15(21.42)$ \\
\hline Can Self Medication be responsible for drug resistance & $92(92.9)$ & $7(7.07)$ & $68(97.14)$ & $2(2.85)$ \\
\hline Do you know about generic and branded medicines & $88(88.88)$ & $11(11.11)$ & $29(41.42)$ & $41(58.57)$ \\
\hline Do you know about merits and demerits of Self Medication & $90(90.90)$ & $9(9.09)$ & $50(71.42)$ & $20(28.57)$ \\
\hline
\end{tabular}

As far the knowledge regarding self medication, 99\% MBBS students and 70\% BDS students knew about it. $89 \%$ of MBBS and $78.57 \%$ of BDS students knew about over the counter drugs. $92.9 \%$ of MBBS students and $97.14 \%$ of BDS students felt that there is a higher risk of ADR's with self medication. $88.88 \%$ of MBBS students think that Drug resistance is promoted by self medication compared to $41.42 \%$ of BDS students. Regarding the knowledge of generic and branded medicines $90.90 \%$ MBBS while only $71.42 \%$ of BDS students knew about them. When asked about merits and demerits $88.8 \%$ MBBS while $97.14 \%$ BDS students said yes (Table 2).

\section{Attitude}

As per as the attitude was concerned only $20.20 \%$ of MBBS students admitted that they recommend self medication to others as compared to $60 \%$ of BDS students.8.08\% of the MBBS students felt that self medication is safe compared to $5 \%$ of BDS students. Majority (75.75\%) of MBBS students feel that self 
medication is very helpful in common diseases like common cold, headache, gastritis etc. as compared to $64.3 \%$ of BDS students. $92.9 \%$ MBBS and $97.14 \%$ BDS students believe that there is risk of wrong medication with self medication. $88.8 \%$ of MBBS students and only
$45.71 \%$ BDS students say that course of medication should be complete even if the symptoms subside. Most of MBBS students $(85.85 \%)$ admitted to reuse the old prescription while $94.3 \%$ of BDS students admitted to reuse of prescription (Table 3).

Table 3: Questions pertaining to the attitude of self medication.

\begin{tabular}{|lllll|}
\hline Particulars & \multicolumn{3}{c|}{ MBBS $(\mathbf{n} \%)$} & \multicolumn{2}{c|}{ BDS $(\mathbf{n} \%)$} \\
\hline Self medication should be recommended to others & Yes & No & Yes & No \\
\hline Is self medication safe & $20(20.20)$ & 79.8 & $42(60)$ & $28(40)$ \\
\hline Self medication should be promoted in treating common diseases & $8(8.08)$ & 91.92 & $2(5)$ & $68(97.14)$ \\
\hline Is there a risk of wrong medication with self medication & $75(75.75)$ & 24.25 & $45(64.3)$ & $25(35.71)$ \\
\hline $\begin{array}{l}\text { The course of medication should be complete whether the symptoms } \\
\text { subside }\end{array}$ & $92(92.9)$ & 7.1 & $68(97.14)$ & $2(2.85)$ \\
\hline Do you use old prescriptions for similar symptoms & $88(88.8)$ & 11.2 & $32(45.71)$ & $38(54.28)$ \\
\hline
\end{tabular}

Table 4: Questions pertaining to the practice of self medication.

\begin{tabular}{|lllll|}
\hline Questions of Practice & \multicolumn{2}{ll}{ MBBS (n\%) } & \multicolumn{2}{l|}{ BDS (n\%) } \\
\hline Most common/routinely used route of self medication & \multicolumn{1}{l}{ Yes } & No & \multicolumn{2}{l|}{ Yes } \\
\hline $\begin{array}{l}\text { Have you ever checked the manufacturing and expiry date before } \\
\text { taking medicines }\end{array}$ & $98(98)$ & $1(1.01)$ & $62(88.57)$ & $8(11.42)$ \\
\hline Have you ever encountered any ADR due to self medication & $5(5.05)$ & $94(94.94)$ & 0 & 0 \\
\hline Have you ever combined herbal and allopathic medicines & $22(22.22)$ & $77(77.77)$ & $2(5)$ & $68(97.14)$ \\
\hline Are you habitual to any medicine without prescription & $25(25.25)$ & $74(74.74)$ & $6(8.57)$ & $64(91.42)$ \\
\hline
\end{tabular}

\section{Practice}

As far the practice, oral route was the most preferred route of self medication by both the groups (96\% MBBS and $100 \%$ BDS). $98 \%$ of MBBS students were aware of checking the manufacturing and expiry date during the course of self medication but practice of looking these dates was lesser in BDS students $(88.57 \%)$. ADR's encountered during self medication by MBBS students were $5.05 \%$ while no ADR was reported by BDS students. $22.22 \%$ MBBS students and only 5\% BDS students practice combining herbal with allopathic medicines. $25.25 \%$ MBBS students and 5.57\% BDS students admitted of being habitual of some medicines without prescription (Table 4).

Major indication of self medication in both the groups was pain $29.3 \%$ in MBBS and $25.71 \%$ in BDS students followed by fever $20.20 \%$ in MBBS and $21.42 \%$ in BDS students. Self medication was a common practice for cough and cold $18.18 \%$ in MBBS and $17.14 \%$ in BDS, nausea and vomiting $15.15 \%$ in MBBS and $11.42 \%$ BDS followed by insomnia $4.04 \%$ MBBS and $11.42 \%$ in BDS. Dysmenorrhoea was also included in both the groups $8.08 \%$ in MBBS and $10 \%$ in BDS students. Even though the anti-anxiety drugs were also there in both the groups but to a lesser extent $5.05 \%$ in MBBS and $2.85 \%$ in BDS student (Table 5).

Table 5: Indications for self-medication.

\begin{tabular}{|lll|}
\hline $\begin{array}{l}\text { Indications of self } \\
\text { medication }\end{array}$ & MBBS $(\mathbf{n} \%)$ & BDS (n\%) \\
\hline Pain & $29(29.3)$ & $18(25.71)$ \\
\hline Fever & $20(20.20)$ & $15(21.42)$ \\
\hline Cough and cold & $18(18.18)$ & $12(17.14)$ \\
\hline Nausea / vomiting & $15(15.15)$ & $8(11.42)$ \\
\hline Insomnia & $4(4.04)$ & $8(11.42)$ \\
\hline Dysmenorrhoea & $8(8.08)$ & $7(10)$ \\
\hline Anxiety & $5(5.05)$ & $2(2.85)$ \\
\hline
\end{tabular}

Analgesics (43.33\% MBBS and $42.85 \%$ BDS) followed by Antipyretics (18.18\% MBBS and $22.85 \% \mathrm{BDS}$ ) and Antacids (14.13\% MBBS and14.28\% BDS) were the most commonly used self-medicated group of drugs in both the study populations. The use of antibiotics (9.09\% MBBS and $11.42 \%$ in BDS), antispasmodics (7.07\% MBBS and $4.28 \%$ in BDS), antianxiety (6.06\% MBBS and $2.85 \%$ in BDS) and antiallergics (4.04\% in MBBS and $1.42 \%$ in BDS students) were among the other category of self medicated drugs used (Table 6). 
Table 6: Category of drugs used for self-medication.

\begin{tabular}{|lll|}
\hline $\begin{array}{l}\text { Medicines used for } \\
\text { self medication }\end{array}$ & MBBS (n \%) & BDS (n \%) \\
\hline Analgesics & $39(43.33)$ & $30(42.85)$ \\
\hline Antipyretics & $18(18.18)$ & $16(22.85)$ \\
\hline Antacids & $14(14.14)$ & $10(14.28)$ \\
\hline Antibiotics & $9(9.09)$ & $8(11.42)$ \\
\hline Antispasmodics & $7(7.07)$ & $3(4.28)$ \\
\hline Antianxiety & $6(6.06)$ & $2(2.85)$ \\
\hline Antiallergics & $4(4.04)$ & $1(1.42)$ \\
\hline
\end{tabular}

Books were the main source of information seen commonly in both MBBS (78.78\%) and dental students $(64.28 \%)$. The use of internet was found to be slightly more in dental students $(22.85 \%)$. Pharmaceutical advertisements (MBBS4.04\% and BDS (7.14\%), senior doctors (MBBS $4.04 \%$ and BDS 2.85\%) and friends (MBBS $1 \%$ and BDS 2.85\%) also contributed as a source of information in both the groups.

\section{Table 7: Sources of information about} self-medication.

\begin{tabular}{|lll|}
\hline Source of information & MBBS (\%) & BDS (\%) \\
\hline Books & $78(78.78)$ & $45(64.28)$ \\
\hline Internet & $12(12.12)$ & $16(22.85)$ \\
\hline $\begin{array}{l}\text { Pharmaceutical } \\
\text { advertisements }\end{array}$ & $4(4.04)$ & $5(7.14)$ \\
\hline Senior doctors/peers & $4(4.04)$ & $2(2.85)$ \\
\hline Friends & $1(1)$ & $2(2.85)$ \\
\hline
\end{tabular}

\section{DISCUSSION}

Self medication is reported to be common among students and out of these medical students form a peculiar group where it is much higher as they have knowledge about the medicines usage.

There has been number of studies which are evaluated on KAP among MBBS students regarding self medication. However, there are a few studies among dental students. But we have come across limited studies regarding comparative evaluation among MBBS and dental students. ${ }^{6,7}$ Therefore the present study was conceived to examine and compare the KAP among these two groups. The knowledge score was more in MBBS students than the BDS students. In the current trial $99 \%$ of the MBBS students were aware of self medication compared to $70 \%$ in dental students. $89.8 \%$ of MBBS students knew about over the counter drugs while for BDS students the figure was only $78 \% .92 .9 \%$ MBBS students had the view that ADR's could be due to inappropriate self medication compared to $97.14 \%$ of BDS students. $88.88 \%$ of MBBS students felt that drug resistance could be due to self medication while only $41.42 \%$ BDS students also felt that resistance could be due to self medication. Similarly, knowledge about generic and branded and merits and demerits were also very high $(88-90 \%)$ among MBBS students as compared to BDS students (50-68\%). There are number of studies those have also recorded similar observation in MBBS students like our trial results. ${ }^{8-10}$ The outcome of knowledge shows that it is higher among MBBS than in dental students which can be easily explained as per the curriculum of the study syllabus of these two groups which is extensive in MBBS students that entails eighteen months of study while in dental it is about twelve months. As far as attitude was concerned there were almost similar scores among most of the questions in both the groups.

However, in practice there was a difference among MBBS and BDS students as none of the students in BDS ever encountered an ADR while 5\% MBBS students stated that they had encountered ADR's due to self medication. Similarly, $22.22 \%$ of MBBS students stated that they had combined herbal and allopathic medicines compared to $5 \%$ in BDS group. $25.25 \%$ MBBS students admitted that they were habitual of taking medicines without prescription while only $8 \%$ BDS students were habitual. The indications for taking self medication were almost identical among both the groups. The chief indication being pain and common cold. Most common drugs used for self medication purpose were analgesics and antipyretics. Similar observations have also been made in the past by numerous authors. ${ }^{11-14}$

\section{CONCLUSION}

The results of current trial show that self medication is prevalent among medical and dental students though the knowledge regarding self medication appeared to be more among medical students but the pattern of attitude and practice was almost similar. Books remained the main source of information while the internet usage was a healthy indication. The outcome of the study also suggests that curriculum regarding ADR teaching should be more encouraged.

\section{Funding: No funding sources \\ Conflict of interest: None declared}

Ethical approval: The study was approved by the Institutional Ethics Committee (No IEC/2018/583)

\section{REFERENCES}

1. Khajuria V, Gupta S, Arora S, Sadiq S. Self medication in dermatological conditions-A Northern Indian Tertiary Hospital Experience. RJPBCS 2013;4(1):247-51.

2. Mehta RK, Sharma S. Knowledge, Attitude and Practice of self medication among medical students. IOSR-JNHS. 2015;4(1):89-96.

3. Shaik T, Mehar BR. A questionnaire based study to assess the knowledge, attitude and practice (KAP) of rationale use of antibiotics among undergraduate dental students in a tertiary care dental hospital of South India. Int $\mathrm{J}$ Basic Clin Pharmacol. 2017;6(2):312-5. 
4. Balamurgan E, Ganesh K. Prevalance and pattern of self medication use in coastal regions of South India BJMP. 2011;4(3):a428.

5. Business World. India emerges as top five pharmaceuticals markets of the world,2018. Available at: http:// business world.in/article/india-emerges-astop-five-pharmaceuticals-market of the world/05-052018-148349. Accessed 26 Oct 2018.

6. Singla S, Kaur M, Mahajan R. Pattern and practice of self medication in students of health professional university in North India. Int J Basic Clin Pharmacol. 2017:2607-11.

7. Kumari R, Kumar D, Bahl R, Gupta R. Study of knowledge and practices of self medication among medical students at Jammu. Journal of Medical Sciences. 2012;15(2):141-4.

8. Patil SB, Vardhamane SH, Patil BV, Santoshkumar J, Binjawadgi AS, Kanaki AR. Self-medication practice and perceptions among undergraduate medical students: a cross-sectional study. Journal of clinical and diagnostic research: JCDR. 2014 Dec;8(12):HC20.

9. Kumar R, Goyal A, Podhy BM, Gupta YK. Self medication practice and factors influencing it among medical and paramedical students in India: A two period comparative cross sectional study. J Nat Sci Biol Med. 2016;7(2):143-8.

10. Shah AK, Rathore RS, Datir NP. Assessment of self medication among dental students: An institution based survey in a dental college at Vadodra, Gujarat. The Health Agenda. 2015;3(3).

11. Sankdia RK, Agarwal M, Rekha PB, Kothari N. A questionnaire based study regarding the knowledge, attitude and practice of self medication among second year undergraduate medical students. IJPCS. 2017;6(1):1-5.

12. Zafar SN, Syed R, Waqar S, Zubairi AJ, Vaqar T, Shaikh M, et al. Self-medication amongst university students of Karachi: prevalence, knowledge and attitudes. J Pak Med Assoc. 2008;58(4):214.

13. James H, Handu SS, Al Khaja KA, Otoom S, Sequeira RP. Evaluation of the knowledge, attitude and practice of self-medication among first-year medical students. Medical principles and practice. 2006;15(4):270-5.

14. Thadani S, Salman MT, Ahmad A. Knowledge, attitude and practice of self medication among second year undergraduate medical students. J Rational Pharmacother Res. 2013;1(3):131-4.

Cite this article as: Rani N, Sadiq S, Khajuria K. Comparative study of knowledge, attitude and practice of self-medication among undergraduate students of MBBS and BDS. Int J Basic Clin Pharmacol 2018;7:2314-8. 